\section{Thomas Aichner}

is a PhD student in Management

Engineering at the Department of Management and Engineering of the University of Padova. He earned his BSc in Economics and Management at LUSPIO University, his MSc in European Business at ESCP Europe and his MA in Management at the University of Trento. His research is mainly focused on mass customization, e-commerce and international marketing.

\section{Paolo Coletti}

is a researcher at the School of Economics and Management of Free University of Bozen Bolzano, Italy, where he is also a lecturer on Information Systems and Data Management courses. He is an expert in applied statistical analysis and has published articles and books in different fields, such as tourism surveys, new technologies for financial news and mass customization case studies. His most recent co-authored book was published in 2012: Projects Handling and Clinical Risk Management, Transferring Theory to Operative Context

Keywords: mass customization; product personalisation; customer survey; electronic commerce; mass customization marketing
Paolo Coletti

School of Economics and Management

Free University of Bozen Bolzano, Universitätsplatz 1 - piazza Università, 1, 39100 Bozen-Bolzano, Italy Tel: +390471011000 Fax: +390471 011009

\section{Customers' online shopping preferences in mass customization}

\author{
Thomas Aichner and Paolo Coletti \\ Received (in revised form): 8th July 2013
}

\begin{abstract}
Mass customization has become important to business because of the difficulties for customers in finding what they want despite an increase in product variety for many categories over the past decades. The emergence of modern technologies in production and communication, however, allows companies to offer customised products and services without relinquishing economies of scale. The advent of web interfaces has finally given the opportunity to achieve completely the involvement of the customer in the product's entire design process. The results of our survey on more than 500 European customers show a declining willingness of customers to compromise on the issue of suitability of products to their personal needs and preferences, the possibility for companies to break brand loyalty through mass customization and the influence of immediate availability, delivery time and price on the customer's willingness to take part in the co-creation process of products. Journal of Direct, Data and Digital Marketing Practice (2013) 15, 20-35. doi: $10.1057 /$ dddmp.2013.34
\end{abstract}

\section{Introduction}

Mass customization is the strategy to offer affordable goods and services with a high variety of personalisation options. It finds its roots in basic human needs: ${ }^{1,2}$ since humans found a way to satisfy basic physical needs, attention has been redirected towards personalising products in order to improve the personal utility of a product ${ }^{3}$ and to show personal status and power. However, only the use of mass production and assembly line technology for personalisation purposes ${ }^{4}$ made personalised products available to a growing number of customers at a reasonable price. The cost of a handmade personalised product is so remarkably high compared to the price of the same product created through mass production that often its appeal is minimal.

This is why today many customised products are mass-produced and mass-customized, which means that customers enjoy the advantages of economies of scale together with a level of personalisation previously only possible with the craft of an artisan.

Cars are the typical example of a product that has undergone all these steps. The first cars built during the nineteenth century were almost entirely handmade, with large possibilities for personalisation due to very small 


\section{Customers enjoy the advantages of economies of scale together with personalisation}

\section{At least one aspect of design, fabrication, assembly or distribution is carried out according to customer's specifications}

Table 1: Trend in product variety (number of models) for some products in the USA

\begin{tabular}{lrrr}
\hline Product & 1970 & 1998 & 2012 \\
\hline Automobile models & & & 684 \\
Newspapers & 140 & 260 & $>5,000$ \\
TV screens (size) & 339 & 790 & 43 \\
Movies (at the cinema) & 5 & 15 & 1,410 \\
Breakfast cereals & 267 & 458 & 4,945 \\
Types of milk & 160 & 340 & $>50$ \\
Mouthwash & 4 & 19 & 113 \\
Sports shoes & 15 & 66 & 3,371 \\
Brands of mineral water & 5 & 285 & 195 \\
Types of tights & 16 & 50 & 594 \\
\hline
\end{tabular}

volumes. Then, at the turn of the century, mass-produced cars appeared, such as the famous Ford Model T and Model A, with costs going constantly down and demand going up. However, the most remarkable feature of these cars was their omnipresent black colour without any possible customer choice. ${ }^{5}$ Slowly, production became more flexible and, starting with the choice of colours in the 1960s and engines in the 1970s, by the 1980s a lot of customisation options were available to buyers. Now a vast set of add-ons, variants and engines is available to every potential buyer, even though customised cars are usually slightly more expensive and their assembly and delivery still require more time compared to an already produced and ready-to-sell model.

One of the main characteristics of modern economic systems is the rise of product variety offered by enterprises. Analysing the US market from 1970 to 2012, for example, the increase in product variety can be seen in Table 1.

The more the number of total variations increases, the less likely it is that the potential customer will be able to find the preferred variation in stock. Therefore, the customer who wants a personalised product must be willing to wait longer. On the other hand, variation increases the possibility to offer a product that best meets the customer's specific preferences and needs.

However, the wide variety offered to potential buyers is still not mass customization. Only when the customer not only has the possibility to choose among many variants, but also has the chance to customise a product individually is mass customization achieved. ${ }^{7}$

The concept of customisation can be explained by considering the operational activities of a generic manufacturing enterprise: design, fabrication, assembly and distribution. A product can be defined as customised when at least one of these operational activities is carried out according to the customer's specifications. ${ }^{8}$ The level of customisation depends on the technology used by the enterprise. Using modern computerisation and robotics, assembly-line technology has been improved and has become more flexible in many ways. Computers and information systems are crucial and a necessary pre-requisite for mass customization, which enables the customer to take part in one or more 


\section{Choice of the right interface}

steps in the creation of a product. It is evident that customer preferences should ideally be integrated in the entire design and production process, even though this is rarely the case in practice. ${ }^{9}$

Moreover, effective mass customization means that the customer cannot merely personalise the product, but can also gain the advantages of economies of scale where price and delivery times are possibly identical to those of a mass-produced product. ${ }^{10-13}$ This is not only intrinsic to the concept definition, but also a necessary marketing feature because customers are drawn to personalised products by the desire to possess their self-designed object without paying the high price of craft manufacturing. Price is therefore an essential part of the customer's desire; otherwise, the individual would turn towards traditional craftsmanship in the event of mass-produced prices, which are too high. Moreover, when the buyer is involved in the production process, either at the design or assembly stage, he/she invests his/her time and competencies in this task - an extra cost in terms of time on top of any other extra cost for customisation.

Another important issue connected to extra costs is extra delivery time. Standardised products, whether mass-produced or handmade, are available immediately and customers have become used to zero waiting time. A personalised product not only needs time for the buyer to express his/her preferences, but might also require more time to be produced and to reach its final destination. This issue must be seriously considered because while for some products immediate availability is not strictly necessary for others buyers might give up.

\section{Mass customization in electronic commerce}

The advent of the internet - and in particular the graphical, interactive World Wide Web - marks an important turning point in mass customization. ${ }^{14}$ Web interfaces are the ideal tool for a dialogue with the potential customer, providing necessary information about the product and collecting his/her preferences in a totally automatic way. This considerably reduces the time and costs for the first step of the product's customisation and can turn the buyer's work into a pleasant experience, which can further induct the desire for a personalised object. In fact, the use of web-based configurators is one major trend in mass customization. ${ }^{15}$

Therefore, the choice of the right interface is clearly a crucial one, since, at the same time, it must be easy to use, complete and offer the user all the possible choices, and with good default choices. An easy-to-use interface avoids frustrating a non-expert customer and keeps him/her from judging the personalisation task as being too difficult and thus leaving it. (There is recent research on product configurators that self-adapt to different levels of customer knowledge in order to reduce this risk. ${ }^{16}$ ) An interface must also be complete, in the sense that it must present to the user all the possibilities and each one with a clear indication of the impact on the final result. This is usually achieved through a product picture that dynamically changes when the customer changes parameters, even though this solution works only for customisation in the assembly stage. 


\section{Dynamic display of final result, maximum freedom, default choices, complexity dependant on user's expertise}

However, a too wide choice of configuration options may lead to an 'overchoice-effect' ${ }^{17}$ and the customer might just give up. Thus, product configurators must be programmed to help avoid this product variety paradox, ${ }^{18}$ for example by hiding certain customisation options at early customisation steps. Nevertheless, a high degree of freedom in terms of design and decisional control over the process enhances the so-called 'I designed it myself' effect, which has a positive impact on the customer's perceived value purely from the fact that he/she designed the product. ${ }^{19}$

Finally, the web interface must have default choices that speed up those potential buyers who do not need deep personalisation or who do not have enough skill or time to go through all the possible options. Clearly, the choice of these defaults must be very precise and possibly dynamically based on other individual customer's preferences or choices obtained through user-profiling techniques. Aside from a functional and userfriendly interface, additional online services such as visualisation and sales person interaction increase customer intention to use online mass customization. ${ }^{20}$

Choi et $a .^{21}$ have suggested a three-dimensional model for electronic commerce, which can be easily extended to electronic mass customization. The three dimensions (see Figure 1) are the product dimension, which states the physical or intangible aspects of the object, the player dimension, which defines the way the buyer interacts with the producer, and the process dimension, which distinguishes different ways for controlling the production process. Kaplan and Haenlein ${ }^{9}$ use the example of a customised newspaper: as long as it is printed on paper (physical product), assembled with a direct interaction with the clerk (player process), based on user preferences expressed to an employee (physical player), it is an example of traditional mass customization. However, each of these three dimensions can be digitalised: the preference-gathering process can be transferred to a web interface, the assembling stage can be fully automated with the help of an appropriate program, while the newspaper itself can become a digital electronic newspaper.

Although most companies offer their products for a similar price as the same, non-customisable products, there is one critical point in electronic

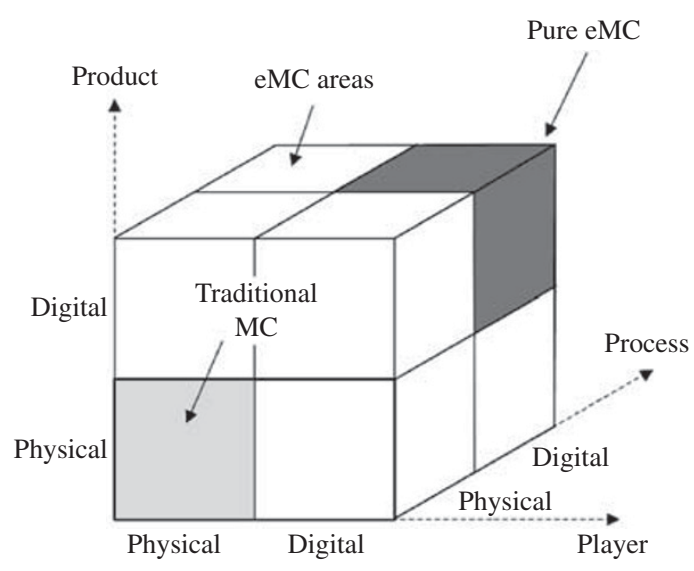

Figure 1: $\quad$ Modified Choi, Stahl and Whinston model ${ }^{9}$ 


\section{Sample and methodology}

\section{Nike provided a live example}

mass customization. As customised products have to be dispatched, the customer has to add additional costs for shipping and handling. Especially for low-cost articles, shipping and handling costs can be more than the price of the article itself. Thus, it would be favourable for companies to find inexpensive delivery solutions in the short run, since this represents extra cost for the buyer and, as we have seen before, it is a crucial point for effective mass customization. In the medium term, shipping and handling must approximate zero.

There are currently many solutions that can be borrowed from standard electronic commerce, which has exactly the same problems. Intensive cooperation with dispatchers and with other companies is recommended. An increasing number of available products will reduce costs, especially if several orders can be combined together. Free shipping and handling is not an impossible challenge, as the book industry shows. ${ }^{22,23}$ Another possible solution is co-operation with existing shop chains, which have many points of sale, possibly adding also local independent shops that can act simply as distributors to this network, as is already done by many online companies (for three different strategies, see chl.it, Wal-Mart's in-store pick up and vendornet.com). ${ }^{23,24}$ With this solution, shipping costs for the manufacturer can be drastically reduced and, at the same time, customers would have the advantage of personal dispatch from a face-to-face reference person who represents the producer.

\section{Survey}

A survey was conducted with the aim of exploring the potential markets for personalised products from a customer's point of view. The sample consists of 561 European respondents aged 16 years or older. Particular care has been taken in balancing male ( 50.8 per cent) with female subjects, and students ( 25.3 per cent), who are probably more prone to new technologies, with non-students. Concerning age distribution, the questionnaire was submitted to people aged from 16 to 86 years with a particular emphasis on young adults (median 28 years, mean 31.9, standard deviation 12.0), since they are the ones who currently use most online services and who will be the largest share of the consumer market in terms of total expenses in the near future. Nationality of respondents is strongly focused on the central European area, with Italy (69 per cent), Austria (12 per cent) and Germany ( 8 per cent) having the largest frequencies.

A staff of English-, German- and Italian-speaking assistants was trained and put in charge of assisting respondents in filling in the questionnaire, with clear instructions to interact only in case of problems in understanding the questions and avoiding any possible suggestion. Each respondent was allowed to choose whether to answer the questions in English, German or Italian. Furthermore, all respondents read the questions and ticked the answers by themselves. (The questionnaire can be found in the Appendix.)

Since the questionnaire includes some jumps (e.g. for people who absolutely do not want to shop online), some answers in questions 5 and 11 are deliberately redundant to check previous answers and to prevent 


\section{Identifying four aspects critical to web marketing}

\author{
Prices and availability
}

\section{Price is the main source of customers' attraction}

subjects ending up in the wrong section feeling lost. Moreover, since some questions involve product personalisation, the questionnaire provides a brief explanation through a short text and, as an example, a picture of Nike's sneaker customisation website.

Preliminary questions on usage of the internet have been asked in order to study possible relations between customisation attitude and internet usage. This showed that 92 per cent of respondents have at least some internet access, with the largest part at home or at work (78 per cent and 75 per cent, respectively). Male users display a significantly larger usage of internet via mobile phones ( 26 per cent for male, 11 per cent for female - chi-square 15.6 with significance 0.000 ) and, as we see in the next section, this has an impact on online-shopping habits, but not on customisation attitude.

Answers were analysed in order to search for results that may be interesting for web marketing purposes, focusing in particular on these four key aspects:

1. price and availability as reasons for shopping online;

2. delivery time as a possible limit for personalised products;

3. brand fidelity as a barrier for the success of personalisation; and

4. an analysis of personalisation intention based on endogenous factors (originating from within the sample).

The first topic of study for a successful marketing strategy on mass customization is the reason why customers buy or do not buy online, which leads to considerations that can be applied to product personalisation via websites. The survey divides the subjects into two groups: those who have already shopped online (48 per cent) and therefore have experience and a clear idea of its characteristics, and those who have never had the chance to shop online, among whom 14 per cent declare having no intention of doing it in the future. The most important reason that has pushed customers to buy or which might push them to buy in the future is price: it is the main reason to do it for online buyers (65 per cent) and a reduction to half price - not so rare in many online shops - is able to make 25 per cent of the non-online buyers change their attitude.

Thus, price is the first element that mass customization websites must keep under control, since it is the main source of customers' attraction. A price increase might drive both old and potential new customers back to traditional shops or, at least, to non-customisable products. This is also confirmed by other studies, ${ }^{25,26}$ which examine the demand curve for consumers and its price flexibility.

The second aspect that pushes customers to shop online is product availability. There are many examples of products that are not easily found in small, traditional shops, especially concerning large product variety. Availability is in fact the second driver for online buyers (52 per cent), while the percentage of non-online buyers who may be convinced to change their habits by availability is only 19 per cent. This is a surprising result, considering that it implies that the remaining 81 per cent of non-online buyers would prefer not to buy the product at all. 


\section{Products that cannot be personalised by traditional shops build loyalty}

\section{Personalisation intention}

Probably it is due to the fact that they do not have experience of the wide range of products available on the internet and therefore have never seen the reduced number of products of traditional shops as a limitation. A similar effect can also be observed in the next section.

The impact of availability, even in a reduced form for non-online buyers, is another aspect that must therefore be carefully considered when planning a mass customization online shop. Offering products - and especially personalisation - which cannot be offered by traditional shops will bind many customers to personalised products, since they will start to see the limitations of the low range in traditional shops.

Availability is a crucial point for a mass customization towards online buyers since people who shop online for a larger product availability have expressed a significantly stronger positive decision (chi-square 8.8 with significance 0.032 ) when asked for their personalisation intention, as can be seen from Table 2 .

A direct question was posed to the respondent as to whether he/she would like to personalise products, after a brief description of online mass customization and a brief example using Nike's website. This gave a result of 43 per cent yes, 39 per cent probably yes, 10 per cent probably no and 8 per cent no. Thus, the large majority of subjects want, or probably want, to personalise. These percentages are calculated on people who have an internet connection and who have at least a minor interest in shopping online in the future. Online customers are generally sensitive to personalisation and prefer online shops that offer personalisation services. ${ }^{27}$ In this light, the result is even more interesting, since it clearly demonstrates that consumers with some experience on the internet are ready to switch from online shops to mass customization online shops, provided that products are offered with the constraints on price and delivery times illustrated in previous sections.

Having a large experience with online shopping already increases significantly (chi-square 16.2 with significance 0.001 ) the desire to try out personalised products, as can be seen in Table 3. This effect is similar to the one in the previous section, where people with a large experience have a much clearer idea of the advantages of the buying process. In addition, it is probably influenced by previous positive experiences, which results in a higher willingness to try new features.

Even though male respondents are usually more in favour of shopping online than their female counterparts, the personalisation intention does

Table 2: Distribution of personalisation intentions by shopping because of availability

\begin{tabular}{lccccc}
\hline Would like to personalise & \multicolumn{2}{c}{$\begin{array}{c}\text { Shop online because product is not } \\
\text { available in traditional shops }\end{array}$} & & \multicolumn{2}{c}{ Shop online for other reasons } \\
\cline { 2 - 3 } \cline { 5 - 6 } & Frequency & Percentage (\%) & & Frequency & Percentage (\%) \\
& 122 & 49 & & 79 & 36 \\
Yes & 85 & 34 & & 100 & 45 \\
Probably yes & 24 & 9 & & 25 & 11 \\
Probably no & 19 & 8 & & 17 & 8 \\
No & & & &
\end{tabular}


Table 3: Distribution of personalisation intention by internet use for online shopping

\begin{tabular}{lccccc}
\hline \multirow{2}{*}{ Would like to personalise } & \multirow{2}{*}{ Use of internet for online shopping } & & \multirow{2}{*}{ Use of internet for other reasons } \\
\cline { 2 - 3 } \cline { 5 - 6 } & Frequency & Percentage (\%) & & Frequency & Percentage (\%) \\
\hline Yes & 121 & 50 & & 80 & 35 \\
Probably yes & 88 & 37 & & 97 & 42 \\
Probably no & 22 & 9 & & 27 & 12 \\
No & 10 & 4 & & 26 & 11 \\
\hline
\end{tabular}

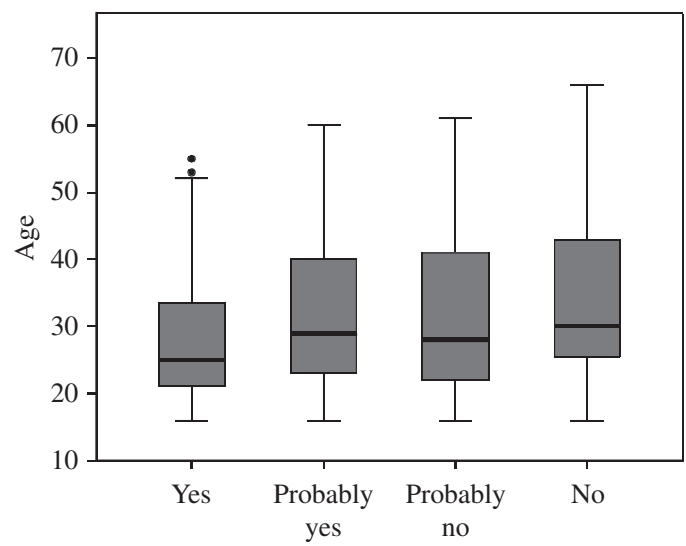

Would like to personalize

Figure 2: Distribution of age by personalisation intention

not show significant (chi-square 1.9 with significance 0.585 ) dependence on sex. This result is a clear indication that, while internet and online shopping remain traditionally male-dominated fields, female consumers represent an already mature potential source for customers.

On the other hand, age does play a major role in the personalisation intention. As can be seen in Figure 2, people who do not want to personalise are slightly older (Kruskal-Wallis test for equality of distributions 16.2 with significance 0.001 ; Jonckheere-Terpstra test for order of distributions 41,212 with significance 0.000 ) than those most committed to personalisation, even though there are still some young people who absolutely do not want to personalise.

This is an expected result, since younger people are the typical online

Older consumers could be driven to mass customization websites without passing through traditional web shops shoppers. However, if we restrict the analysis to those subjects who do not use the internet for online shopping, therefore concentrating on the future potential buyers, age does not remain significant anymore. This result indicates that older consumers could be driven to mass customization websites directly without passing through web shops that do not offer personalisation of products.

Time is another crucial factor that influences customers' attitude towards mass customization. As it is evident, an over-long production time combined with the extra delivery time that is typical for internet 


\author{
Waiting time tolerance \\ for personalised \\ products
}

\section{Personalisation time must be kept short in order to save time for delivery}

shopping can keep many potential customers from buying online, as well as from trying out online mass customization.

The survey asked respondents to consider the last item bought on the internet and the last item bought in a traditional shop for more than ten euro and checked his/her tolerance on waiting time in the case of product personalisation. The answers clearly have a large variance since they depend strongly on the individual product considered by the subject: for example, for an immediate consumption product, such as food, no waiting time is usually tolerated, while for gifts a larger waiting time is tolerated.

The fact that 16 per cent and 21 per cent of respondents (last item bought on the internet and in a traditional shop, respectively) are ready to wait up to seven days for a personalised product has to be considered a very good result since seven days is a rather long waiting time. This duration allows automated production lines to make the personalised product and even ship it to destination. Further, 14 per cent of people who bought their last item in a traditional shop are willing to add one day of waiting time if personalisation is offered. As one day does not allow for shipping but only for personalisation, these customers might not be willing to change from a traditional to an online shop, even though they are in favour of product personalisation. Another 13 per cent of people who bought their last item in an online shop are ready to add one extra day of waiting time. This means that online shops offering product personalisation can plan to use this extra time completely for the personalisation process because shipping time is already included in their order-to-delivery period.

As shown in Table 4, the majority of people who would personalise the last product bought (35 per cent in a traditional shop and 33 per cent online) want the product to be available with no added waiting time, meaning immediately for people who bought it in a traditional shop and with the same waiting time as for the original product for people who bought the product online. Thus, to satisfy all potential customers companies will have to optimise their operations in order to be able to find the extra time necessary to customise the product without requiring their customers to wait longer than usually.

This seems to be a highly challenging task for traditional shops because people want to take the product away immediately. Online shops have more alternatives to fulfil the customer's expectations. First,

Table 4: Distribution of waiting time for last bought item in traditional shops and in online shop

\begin{tabular}{lccccc}
\hline \multirow{2}{*}{$\begin{array}{l}\text { Would you personalise the last } \\
\text { product you bought? }\end{array}$} & \multicolumn{2}{c}{ Traditional shop } & & \multicolumn{2}{c}{ Online shop } \\
\cline { 2 - 3 } \cline { 5 - 6 } & Frequency & Percentage (\%) & & Frequency & Percentage (\%) \\
\hline & 188 & 35 & & 101 & 33 \\
Yes, if available immediately & 73 & 14 & & 40 & 13 \\
Yes, if available after one day & 83 & 16 & & 65 & 21 \\
Yes, if available after seven days & 186 & 35 & & 102 & 33 \\
No & & & & \\
\hline
\end{tabular}




\section{Brand loyalty as a barrier to entry}

\section{Brand switching differs by product type}

they can improve the production process in order to allow for the extra time necessary for customisation. Second, if the production process cannot be optimised, they can improve shipping, for example by using more sophisticated IT systems or by choosing a faster parcel service.

These results place another condition on successful mass customization implementation: personalisation time must be kept as short as possible in order to be able to deliver the final product to the customer according to his/her personal preferences. As many customers are not willing to wait any longer than usual, for some products personalisation must be an immediate operation, without adding any extra waiting time. This is also confirmed by the previously mentioned studies, ${ }^{25,26}$ which also examined the customer's demand curve flexibility towards delivery time and also proposed a framework for a negotiation between company and customer to reach the equilibrium point that the customer deems as sufficient.

Brand loyalty is one of the best-known marketing strategies used to keep customers. For innovative products, such as personalised products, it can represent a strong entry barrier for many markets. Moreover, the interest and especially ability to personalise changes strongly with product familiarity ${ }^{28}$ and this can represent a further incentive or disincentive towards investing time in customisation.

In order to check which might potentially be open markets, the willingness to change brand in exchange for personalisation was asked to the survey's respondents. Since brand loyalty depends strongly on the product category, especially for electronic commerce, ${ }^{29}$ the question was split into seven different categories: footwear, clothing, sports equipment, computers, dinnerware, toys and gifts. It is important to underline that this question is under the hypothesis of identical price and identical quality, to restrict the result on brand loyalty and eliminate the effect of well-known or low-cost brands.

As shown in Table 5, the percentage of people willing to change brand for the opportunity to personalise the product ranges from 50 per cent to 74 per cent, suggesting that at least half of brand loyalty can be broken by mass customization companies provided price and quality remain the same. The two lowest percentages are for dinnerware ( 50 per cent) and toys (50 per cent), two categories for which people probably do not deem personalisation as so important. The percentage rises to almost 74 per cent

Table 5: Brand change intention when personalisation is offered

\begin{tabular}{lccc}
\hline $\begin{array}{l}\text { Would you abandon your old brand for } \\
\text { a personalised product? 'Yes' answers }\end{array}$ & Female (\%) & Male (\%) & Total (\%) \\
\hline Computer & 50 & 59 & 55 \\
Dinnerware & 56 & 43 & 50 \\
Footwear & 63 & 58 & 60 \\
Clothing & 71 & 66 & 68 \\
Sports equipment & 52 & 53 & 53 \\
Toys & 54 & 48 & 50 \\
Presents & 77 & 71 & 74 \\
\hline
\end{tabular}




\section{Good opportunities for market penetration}

\section{High demand for personalised products}

for gifts, where brands are not so important and where personalisation especially can give a very large plus to the product. This result is also emphasised by another study, ${ }^{30}$ which distinguishes the categories that present conformity from those that present counter-conformity, where clearly customisation becomes much more interesting from the customer's point of view.

When distinguishing between female and male respondents, female subjects display a significantly (chi-square 4.4 with significance 0.041 ) smaller preference only for computers and a significantly (chi-square 8.3 with significance 0.005 ) larger preference for dinnerware, two sectors where typically men and women have different needs and different perspectives.

The analysis of brand loyalty displays that there are good opportunities for market penetration in all the sectors, but it is necessary to target the marketing strategies, specifically to the type of product and, for some types, to the customer's gender since brand loyalty can vary a lot.

\section{Conclusions}

By offering customisable products in a mass production environment, companies expect to realise significant competitive advantage through the generation of enduring customer value..$^{31-33}$ This is attempted by offering the customer a possibly unlimited number of choices to customise a certain product according to his/her individual needs.

Both existing literature and this investigation highlighted two important aspects that influence the customer's choice on whether to rely on a certain company to buy a customised product or not: price and waiting time. Despite the willingness of customers to pay significantly more for selfdesigned versus off-the-shelf-products, ${ }^{31,34,35}$ various studies determine implicitly the fundamental goal of achieving mass customization products at the same price or a marginal higher price as mass-produced products, ${ }^{36,9}$ as well as this study does.

As shown in the previous section, waiting time plays a crucial role in the willingness to use product customisation offers and should be a signal to companies that are offering mass customization not just to concentrate on price equality, but to optimise information and physical flow in order to reduce production and delivery time to a minimum. This can increase operational efficiency decisively.

The result of our survey underlines that there is a high demand for personalised products. This finding is supported by the fact that 52 per cent of respondents say that they do or intend to shop online because of unavailability of the product in a traditional shop. Furthermore, a total of 19 per cent of people who explicitly responded that they neither shop nor intend to shop online in the future would shop online if the product was not available in a traditional shop (see Table 2). These numbers gain in importance by taking into account the negative factors associated with mass customization and online shopping, which include the multifaceted perceived risk when purchasing a customised product, ${ }^{37}$ the payment of a price premium, the acceptance of waiting time and the time and effort involved. ${ }^{26}$ 


\section{Shops will serve little purpose in the future of mass customized products.}

Branding products no longer guarantees loyal customers because triedand-true marketing techniques from the past no longer work for most products - particularly for complex ones based on new technologies. ${ }^{38}$ On the one hand, mass customization is a promising strategy to improve a company's relationship with its customers, ${ }^{39,40}$ which might reward mass customization companies with increased loyalty in exchange for the better fit between the self-designed product and individual preferences. ${ }^{41,42}$ This implies that, on the other hand, customers might be willing to change brand if another company offers a similar product with identical price and identical quality combined with the possibility to customise the product.

At present, traditional shops where finished goods are stored are the main sales platforms for mass-produced goods. Potential customers enter the store and choose among a limited number of displayed products. Despite an increasing product variety (see Table 1), the choice is limited due to the limited exhibition and storage space of a store. In spite of the findings of this investigation, shops will serve little purpose in the future of marketing mass customized products for the following reasons:

- of the total survey respondents, 36 per cent are willing to use customisation in traditional stores only if the product is available immediately (see Table 4). At present, this seems to be a hardly realisable challenge;

- customers would have to come back a second time to the store after a certain period of time. This is connected to both an investment in time and additional costs, for example bus ticket or car park charges; and

- traditional shops would have to provide digital equipment to the customers in order to allow them to personalise the product using a consumer-friendly interface. Further, the order must be digital to be able to forward it to the production plant instantly. A delay at this point would result in a further competitive disadvantage compared to online mass customization.

Finally, 67 per cent of survey respondents of the conducted investigation state that they would rather have bought the last product they bought online on a website that offers the possibility to personalise the product than on the original website, 33 per cent are not willing to accept additional waiting time, whereas 34 per cent would accept slower delivery time (see Table 4).

It is the mass customization companies' responsibility to use cost savings based on the omission of an obsolete traditional retail network to optimise internal communication in order to start the manufacturing process as swiftly as possible. In this way, both the need for personalisation and the desire of customers not to add waiting time can be satisfied.

\section{References}

1. Pine II, B.J., Victor, B. and Boynton, A. (1993) 'Making mass customisation work', Harvard Business Review, Vol. 71, No. 5, pp. 108-119. 
2. Davis, S.M. (1989) 'From "future perfect”: Mass customizing', Strategy \& Leadership, Vol. 17, No. 2, pp. 16-21.

3. Merle, A., Chandon, J.L., Roux, E. and Alizon, F. (2010) 'Perceived value of the mass-customised product and mass customisation experience for individual consumers', Production and Operations Management, Vol. 19, No. 5, pp. 503-514.

4. Bock, S. (2008) 'Using distributed search methods for balancing mixed-model assembly lines in the automotive industry', OR Spectrum, Vol. 30, No. 3, pp. 551-578.

5. Clymer, F. (1950) Treasury of Early American Automobiles, 1877-1925. McGraw-Hill, New York

6. Cox, M.W. and Alm, R. (1998) 'The right stuff: America's move to mass customisation'. 1998 Annual Report. Dallas: Federal Reserve Bank of Dallas.

7. Moser, K. (2007) Mass Customisation Strategies - Development of a Competence-based Framework for Identifying Different Mass Customisation Strategies. Lulu Enterprises, Morrisville, NC.

8. Lampel, J. and Mintzberg, H. (1996) 'Customising customization', Sloan Management Review, Vol. 38, No. 1, pp. 21-30.

9. Kaplan, A.M. and Haenlein, M. (2006) 'Toward a parsimonious definition of traditional and electronic mass customization', Journal of Product Innovation Management, Vol. 23, No. 2, pp. $168-182$.

10. Fogliatto, F.S., da Silveira, G.J.C. and Royer, R. (2003) 'Flexibility-driven index for measuring mass customisation feasibility on industrialised products', International Journal of Production Research, Vol. 41, No. 8, pp. 1811-1829.

11. Hart, C.W.L. (1995) 'Mass customisation: Conceptual underpinnings, opportunities and limits', International Journal of Service Industry Management, Vol. 6, No. 2, pp. 36-45.

12. Lau, R. (1995) 'Mass customisation: The next industrial revolution', Industrial Management, Vol. 37, Nos. 9-10, pp. 18-19.

13. Lee, C.H.S., Barua, A. and Whinston, A.B. (2000) 'The complementarity of mass customisation and electronic commerce', Economics of Innovation and New Technology, Vol. 9, No. 2, pp. 81-109.

14. Turowski, K. (2002) 'Agent-based e-commerce in case of mass customization', International Journal of Production Economics, Vol. 75, Nos. 1-2, pp. 69-81.

15. Fogliatto, F.S., da Silveira, G.J.C. and Borenstein, D. (2012) 'The mass customisation decade: An updated review of the literature', International Journal of Production Economics, Vol. 138, No. 1, pp. 14-25.

16. Fürstner, I., Anišić, Z. and Takács, M. (2012) 'Product configurator self-adapting to different levels of customer knowledge', Acta Polytechnica Hungarica, Vol. 9, No. 4, pp. 129-150.

17. Gourville, J.T. and Soman, D. (2005) 'Overchoice and assortment type: When and why variety backfires', Marketing Science, Vol. 24, No. 3, pp. 382-395.

18. Trentin, A., Perin, E. and Forza, C. (2012) 'Avoiding the variety paradox through product configurators', in Freund, R. (ed) Customer Co-creation in Central Europe. Proceedings of the 5th International Conference on Mass Customisation and Personalisation in Central Europe. 19-21 September, Novi Sad, Serbia, pp. 252-260.

19. Franke, N., Schreier, M. and Kaiser, U. (2010) 'The "I designed it myself effect" in mass customization', Management Science, Vol. 56, No. 1, pp. 125-140.

20. Dellaert, B.G.C. and Dabholkar, P.A. (2009) 'Increasing the attractiveness of mass customization: The role of complementary on-line services and range of options', International Journal of Electronic Commerce, Vol. 13, No. 3, pp. 43-70.

21. Choi, S.Y., Stahl, D.O. and Whinston, A.B. (1997) The Economics of Electronic Commerce. Macmillan Technical Publishing, Indianapolis, IN.

22. Frischmann, T., Hinz, O. and Skiera, B. (2012) 'Retailers' use of shipping costs strategies: Free shipping or partitioned prices?', International Journal of Electronic Commerce, Vol. 16, No. 3 , pp. $65-87$.

23. Starkey, A. (2010) 'e-Retail — Using home delivery as a service differentiator and strategic marketing tool', Journal of Direct, Data and Digital Marketing Practice, Vol. 12, No. 2, pp. $165-173$.

24. Business Wire. (2012) 'Stores can be ultimate merchandise "lockers" for shoppers looking to avoid online purchase delivery hassles', 20 September, available at http://www.businesswire. com/news/home/20120910006080/en, accessed on 14 December 2012. 
25. Songlin, C. and Mitchell, M.T. (1998) 'Aligning demand and supply flexibility in custom product co-design', International Journal of Flexible Manufacturing Systems, Vol. 19, No. 4, pp. 596-611.

26. Bardakci, A. and Whitelock, J. (2003) 'Mass-customisation in marketing: The consumer perspective', Journal of Consumer Marketing, Vol. 20, No. 5, pp. 463-479.

27. Ganesh, J., Reynolds, K.E., Luckett, M. and Pomirleanu, N. (2010) 'Online shopper motivations, and e-store attributes: An examination of online patronage behavior and shopper typologies', Journal of Retailing, Vol. 86, No. 1, pp. 106-115.

28. Loginova, O. (2010) 'Brand familiarity and product knowledge in customization', International Journal of Economic Theory, Vol. 6, No. 3, pp. 297-309.

29. Huang, C.Y. (2011) 'Excess loyalty in online retailing', International Journal of Electronic Commerce, Vol. 16, No. 2, pp. 115-133.

30. Franke, N. and Schreier, M. (2008) 'Product uniqueness as a driver of customer utility in mass customization', Marketing Letters, Vol. 19, No. 2, pp. 93-107.

31. Pine II, B.J. (1993) Mass Customisation: The New Frontier in Business Competition. Harvard Business School Press, Boston.

32. Fiore, A., Lee, S.E., Kunz, G. and Campell, J. (2001) 'Relationships between optimum stimulation level and willingness to use mass customisation options', Journal of Fashion Marketing and Management, Vol. 5, No. 2, pp. 99-107.

33. Reichwald, R. and Piller, F.T. (2006) Interaktive Wertschöpfung: Open innovation, Individualisierung und Neue Formen der Arbeitsteilung. Gabler, Wiesbaden.

34. Franke, N. and Piller, F. (2004) 'Toolkits for user innovation and design: An exploration of user interaction and value creation', Journal of Product Innovation Management, Vol. 21, No. 6, pp. 401-415.

35. Schreier, M. (2006) 'The value increment of mass-customised products: An empirical assessment', Journal of Consumer Behavior, Vol. 5, No. 4, pp. 317-327.

36. Shen, A. and Ball, A.D. (2006) 'How do customers evaluate mass-customised products?' in Grewal, D., Lewy, M. and Krishnan, R. (eds) Proceedings of the Summer American Marketing Association Conference. AMA, Chicago, IL, pp. 388-389.

37. Glover, S. and Benbasat, I. (2010) 'A comprehensive model of perceived risk of e-commerce transactions', International Journal of Electronic Commerce, Vol. 15, No. 2, pp. 47-78.

38. McKenna, R. (1988) 'Marketing in the age of diversity', Harvard Business Review, Vol. 66, No. 5, pp. 88-95.

39. Peppers, D. and Rogers, M. (1999) Enterprise One-to-One: Tools for Competing in the Interactive Age. Broadway Business, New York.

40. Pine II, B.J., Peppers, D. and Rogers, M. (1995) 'Do you want to keep your customers forever?', Harvard Business Review, Vol. 73, No. 2, pp. 103-114.

41. Ansari, A. and Mela, C.F. (2003) 'E-customisation', Journal of Marketing Research, Vol. 40, No. 2, pp. 131-145

42. Simonson, I. (2005) 'Determinants of customers' responses to customised offers: Conceptual framework and research propositions', Journal of Marketing, Vol. 69, No. 1, pp. 32-45. 


\section{Appendix}

\section{Questionnaire}

(1) Name (optional), nationality, residence

(2) Age

(3) Sex

(4) Occupation: student, employed, other (one answer)

(5) Use of internet: (one answer per category)

- at home: yes, in the future, no

- at work/university: yes, in the future, no

- at internet café: yes, in the future, no

- at mobile phone: yes, in the future, no If you ticked 'no' four times, please continue with question 12.

(6) What are you using internet for: to surf, to chat or write e-mails, to book a hotel or a holiday, for online shopping, for online banking, I have not used internet yet (several answers)

(7) Please tick what applies to you: I shop online, I intend to shop online in the future, I may shop online in the future, I will never shop online (one answer)

(8) If you ticked 'I will never shop online', would you shop in at least one of the following cases? If the product were to cost more than 50 per cent less than in a traditional shop, if the product were not available in a traditional shop, no, I would never shop online (one answer)

If you ticked 'no, I would never shop online', please continue with question 12.

(9) Why do you shop online or intend to shop online in the future? for convenience, for low prices, to try out new technologies, because I am not able to find the product in a traditional shop (several answers) mass customization describes the operation of personalising, normally online, a product. This individual personalisation happens step by step via a simple user interface within a few minutes. Customers can individually design the product according to their individual conception by choosing colour, size, writing, pattern, logos, material and so on. The price of such a personalised product corresponds to the price of a traditional, non-personalised, product that can be bought in a traditional shop (picture of personalisation of shoes through Nike website follows)

(10) Would you like to personalise a product online, that is individually choose colour, size, writing, pattern, logos, material and so on? Yes, probably yes, probably no, no (one answer)

(11) Would you prefer to buy the product of a company that offers mass customization rather than of a company that does not offer mass customization? yes, I would prefer to buy the product of a company that offers mass customization, no, I would prefer to buy the product of a company that does not offer mass customization (one answer) 
(12) Referring to the last product you bought online: Would you rather have bought the product on a website that offers you the possibility to personalise the product than on the original website? I have not shopped online yet, yes with identical delivery time, yes if the delivery time were no longer than one additional day, yes if the delivery time were no longer than seven additional days, no I would have bought the product anyway at the original website (one answer)

(13) Referring to the last product you bought in a traditional shop for more than 10 euro/15 dollars, would you rather have bought the product in a shop that offers you the possibility to personalise the product than in the original shop? yes, if the product were available immediately, yes if the product were available after one day, yes if the product were available after seven days, no I would have bought the product anyway in the original shop (one answer)

(14) If you could find a similar product (identical price and identical quality) of a brand that offers personalisation, would you abandon your old brand and change? (one answer per category)

- footwear: yes change, no not change

- clothing: yes change, no not change

- sports equipment: yes change, no not change

- computers: yes change, no not change

- dinnerware: yes change, no not change

- toys: yes change, no not change

- presents: yes change, no not change 